\title{
SISTEM FUZZY PADA KONTROLING AERATOR UNTUK MENINGKATKAN KUALITAS AIR KOLAM PEMBIBITAN IKAN MENGGUNAKAN SENSOR DO DAN SENSOR SUHU
}

\author{
Andi Farmadi1), Muliadi2), Ichsan Ridwan ${ }^{3}$ \\ 1,2,3) Ilmu computer FMIPA,Universitas Lambung Mangkurat \\ 2)Fisika FMIPA,Universitas Lambung Mangkurat \\ Jl.Ahmad Yani Km36, Banjarbaru \\ *)andifarmadi@ulm.ac.id
}

\begin{abstract}
Dissolved oxygen levels in water will affect water quality directly and indirectly for fish life as well as conditions in the water environment, therefore, it is very important to control water quality for adequate dissolved oxygen levels, because this plays an important role in the health condition of the environmental ecosystem for fish nurseries. Researchers usually measure and monitor water quality using measuring instruments that are widely sold in the market, for conditions of decreasing dissolved oxygen levels in fish nurseries tank can usually be controlled by adding an air bubble machine to the water using an aerator machine. Giving air bubbles to water is an effort to control the conditions for the adequacy of dissolved oxygen in the water, and the best system is to carry out a continuous control system regarding water quality, sometimes the oxygen condition in the water is sufficient for the standard of dissolved oxygen in water. However, the blower blower is still running, this is less effective because it requires unnecessary electrical energy or wastes energy. Analysis of the aerator engine control system is needed to make a design as to what state the aerator engine should be turned on. Analysis of the aerator engine control system can be done by measuring the level of oxygen and water temperature in the fish nursery tank, then designing a fuzzy model with the Sugeno inference system for how long the engine must be turned on. The analysis and design of this aerator system is a proposed solution to these problems with a system of measurement and monitoring carried out intelligently by a machine, so that it is able to measure how late this aerator machine must be turned on. and the developed design is capable of being a smart machine using a fuzzy system
\end{abstract}

Keywords: Fuzzy inference, aerator engine, smart system, water quality.

\begin{abstract}
Abstrak
Kadar oksigen terlarut dalam air akan mempengaruhi kualitas air secara langsung dan tidak langsung bagi kehidupan ikan juga keadaan di lingkungan air tersebut, oleh karena itu peningkatan kualitas air untuk keadaan kecukupan kadar oksigen yang terlarut sangat penting untuk dikontrol, karena hal ini berperan penting pada kondisi kesehatan
\end{abstract}


ekosistem lingkungan pembibitan ikan. Para peneliti biasanya melakukan pengukuran dan pemantauan kualitas air dengan menggunakan alat ukur yang banyak di jual dipasaran, untuk kondisi menurunnya kadar oksigen yang terlarut pada kolam pembibitan ikan biasanya dapat di kontrol dengan menambahkan mesin gelembung udara pada air menggunakan mesin aerator. Pemberian gelembung udara pada air merupakan salah satu upaya untuk mengontrol kondisi kecukupan kadar oksigen yang terlarut di dalam air, dan sistem yang terbaik yaitu melakukan sistem kontrol secara terus menerus mengenai kualitas air, terkadang kondisi oksigen di dalam air telah mencukupi standar kecukupan oksigen terlarut pada air, namun mesin penyembur gelembung udara masih dinyalakan, hal ini menjadi kurang efektif sebab akan membutuhkan energi listrik yang tidak semestinya atau terjadinya pemborosan energi. Analisis sistem pengontrolan mesin aerator dibutuhkan untuk melakukan desain seperti apa sebaiknya keadaan mesin aerator dihidupkan. Analisis sistem pengontrolan mesin aerator ini dapat dilakan dengan mengukur tingkat kadar oksigen dan suhu air pada kolam pembibitan ikan, kemudian melakukan perancangan model fuzzy dengan sistem inferensi sugeno seberapa lama mesin harus dihidupkan. Analisis dan desain sistem aerator ini merupakan usulan solusi permasalahan tersebut dengan sistem pengukuran dan pemantauan dilakukan secara cerdas oleh mesin, sehingga mampu mengukur seberapa lalma mesin aerator ini harus dihidupkan desain alat ini juga diharapkan mampu memberikan solusi peningkatan kualitas air pada pembibitan ikan dan diharapan pula analisis dan desain yang dikembangkan ini mampu menjadi mesin cerdas dengan menggukan sistem fuzzy

Kata kunci : Fuzzy inferensi, mesin aerator, Sistem cerdas, kualitas air.

\section{PENDAHULUAN}

Pada kolam pembibitan ikan sistem tatakelola air merupakan hal utama dalam peningkatan kualitas hidup ikan. Pemahaman tentang kandungan unsur hara, kondisi fisik dan kimiawi air merupakan bagian dari sistem pengelolaan yang baik. Sistem pengukuran tentang parameter kualitas air pada kolam pembibitan ikan mutlak diperlukan untuk mengukur kualitas air sesuai standar kualitas air untuk pembibitan ikan, pengukuran tersebut dilakukan secara berkala, pengukuran yang tidak berkesinambungan dapat menyebabkan kondisi lingkungan air menjadi buruk dan menyebabkan kematian bibit ikan, berakibat gagalnya sistem pembibitan ikan yang ada.

Sistem pengelolaan kualitas air salah satunya adalah tingkat kandungan oksigen yang terlarut dalam air, jika kandungan oksigen dibawah dari standart yang ditentukan, maka hal ini dapat menyebabkan hilangnya nafsu makan ikan yang berakibat kematian pada ikan, demikian juga faktor suhu air pada kolam pembibitan ikan, dimana suhu akan berpengaruh pada keaktifan ikan sehingga pengukuran kedua parameter ini menjadi sangat penting dalam sistem pengelolaan kualitas air pada kolam pembibitan.

Pengukuran tingkat DO (Dissolved Oxygen) atau tingkat oksigen terlarut dalam air dan juga pengukuran suhu biasanya menggunakan alat yang banyak dijual dipasaran, namun sistem pengukuran harus dilakukan secara manual atau dilakukan secara langsung oleh pengelola, sehingga tidak dimunkinkan dilakukan pengukuran secara terus menerus, karena akan memakan waktu dan biaya yang tidak sedikit.

Netralisir rendahnya tingkat oksigen terlarut dalam air dan juga suhu, bisanya dilakukan dengan memberikan semburan gelembung udara pada air, sehingga tingkat 
oksigen bisa naik hingga mencapai kondisi kecukupan oksigen yang diharapkan pada kolam pembibitan ikan, pemberian gelembung udara bisanya menggukan mesin aerator yang banyak di jual dipasaran.

Sistem otomatisasi mesin aerator menjadi sangat penting karena selain memberikan penghematan energi listrik, juga dapat menghemat tenaga pekerja, sehingga sistem pemantauan dan pengelolaan kualitas air dapat terwujud. Sistem otomatisasi mesin aerator berupa berapa lama dan seberapa banyak semburannya akan sangat penting dilakukan pada kolam pembibitan ikan untuk meberikan penghematan energi.

\section{METODOLOGI PENELITIAN}

Metodologi penyusunan penelitian mengikuti langkah-langkah dalam kerangka penelitian sistem pakar dengan langkah-langkah sebagai berikut:

a. Penilaian

Pada tahap penilaian dilakukan penentuan mengenai hal penting sebagai dasar dan masalah tingkat kesesuaian, menentukan rumusan masalah, menentukan variabel sistem dalam kesesuaian lahan dan pengumpulan data lapangan sesuai kebutuhan sistem.

b. Akuisisi Pengetahuan dan representasi pengetahuan

Tahap Akuisisi yaitu mengolah semua alur pengetahuan pakar menjadi sebuah rule pengetahuan dalam menentukan kesesuain lahan untuk kelapa sawit pada lahan rawa, dan pengolahan ini nantinya akan menjadi dasar pada representasi pengetahuan. Hasil dari akuisisi pengetahuan kemudian diolah dalam keanggotaan tiap variabel dengan menghitung nilai keanggotaan fuzzy masingmasing variabel, Kemudian dihitung inferensinya menggunakan metode sugeno.

c. Desain

Hasil dan semua tahapan sebelumnya akan dijadikan sebagai dasar dalam tahapan desain.

d. Pengujian

Untuk Menghindari kesalahan dari proses sistem pakar, maka perlu dilakukan pengujian, bila terjadi kesalahan atau bug, maka sistem pakar akan dikoreksi sampai proses yang diingikan tercapai. Untuk rangkaian seluruh jalannya alur pengerjaan penelitian dapat di lihat pada gambar alur penelitian di bawah. 


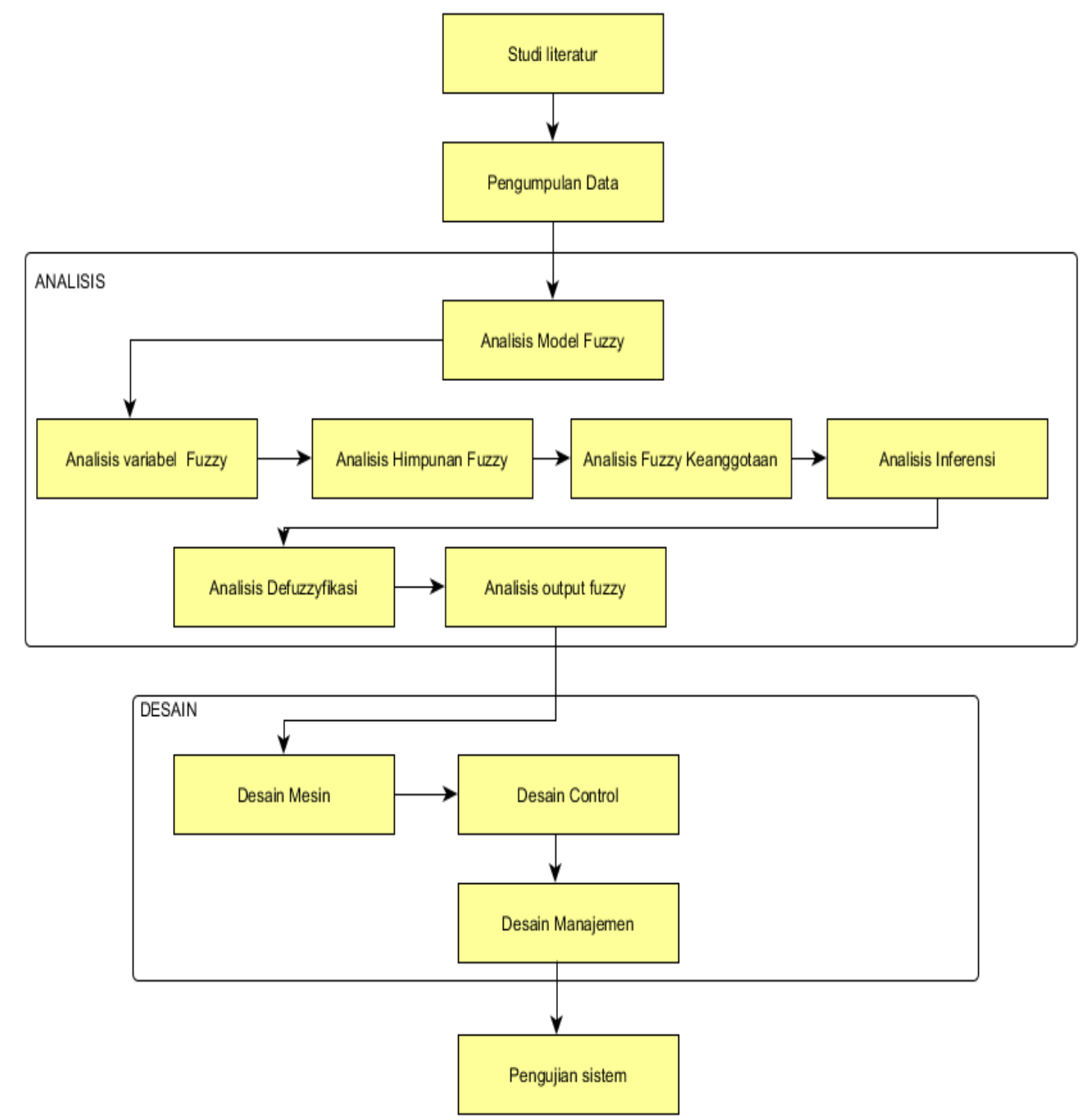

Gambar 1. Bagan alir penelitian

\section{HASIL DAN PEMBAHASAN}

\subsection{Basis Pengetahuan}

Berdasarkan dari data yang didapatkan dari pakar kemudian ditentukan dua kriteria dalam penentuan kualitas air pada kolam pembibitan, yaitu kriteria tingkat suhu air, dan tingkat oksigen yang terlarut dalam air. Data kriteria yang diperoleh adalah sebagai berikut.

a. Kriteria Variabel suhu air

Berikut tingkat kesesuaian suhlu air untuk beberapa jenis ikan air tawar yang sering digunakan dalam pembibitan ikan 
Tabel 1. Kadar Suhu optimum untuk beberapa budidaya ikan

\begin{tabular}{|c|l|c|}
\hline \multicolumn{3}{|c|}{ TABEL SUHU AIR } \\
IKAN AIR TAWAR \\
\hline NO & JENIS IKAN & TEMPERATUR OPTIMUM \\
\hline 1 & TAWES & $20-33 \mathrm{C}$ \\
\hline 2 & NILEM & $18-28 \mathrm{C}$ \\
\hline 3 & MAS / TOMBRO & $20-25 \mathrm{C}$ \\
\hline 4 & PATIN & $28-32 \mathrm{C}$ \\
\hline 5 & BAWAL & $25-30 \mathrm{C}$ \\
\hline 6 & GURAME & $24-28 \mathrm{C}$ \\
\hline 7 & NILA & $25-30 \mathrm{C}$ \\
\hline 8 & SIDAT & $28-29 \mathrm{C}$ \\
\hline 9 & LELE & $25-30 \mathrm{C}$ \\
\hline 10 & GABUS & $25-30 \mathrm{C}$ \\
\hline
\end{tabular}

b. Kriteria Keseuaian pada himpunan fuzzy

Dari data yang diperoleh kemudian disusun himpunan keanggotaan fuzzy untuk tingkat suhu air kolam pembibitan ikan, dengan menetapkan tiga himpunan fuzzy suhu air yaitu kategori dingin, kategori normal dan kategori panas yang kemudian dijadikan sebagai dasar pada pembentukan himpunan fuzzy untuk tingkat suhu air pada kolam pembibitan.

c. Kriteria variabel DO air

Dari data dan penjelasan pakar yang dipeoleh dapat dijelaskan bahwa tidak ada batasan yang jelas mengenai batasan tingkat oksigen pada air, namun dapat dikategorikan keadaan air diberikan tiga kategori tingkat kandungan oksigen yaitu untuk tingkat oksigen terlarut dalam air yaitu keadaan DO rendah, keadaan DO baik, dan keadaan DO air dengan tingkat kandungan oksigen yang tinggi, yang kemudian dijadikan sebagai dasar pada pembentukan himpunan fuzzy untuk tingkat suhu air pada kolam pembibitan.

\subsection{Model Fuzzy}

Model fuzzy yang digunakan adalah model sistem inferinsi menggunakan model sugeno ordo 1 menggunakan output berupa singelto. Menggunakan inputan dengan dua variabel fuzzy yaitu variabel Suhu dengan 3 himpunan keanggotaan yaitu kategori dingin, normal dan panas, inputan yang kedua yaitu menggunakan variabel tingkat Oksigen yang terlarut dalam air atau DO dangan himputnan keanggotaan yaitu rendah, baik dan tinggi untuk outputnya berupa seberapa banyak gelembung udara yang disemburkan oleh mesin aerator. 


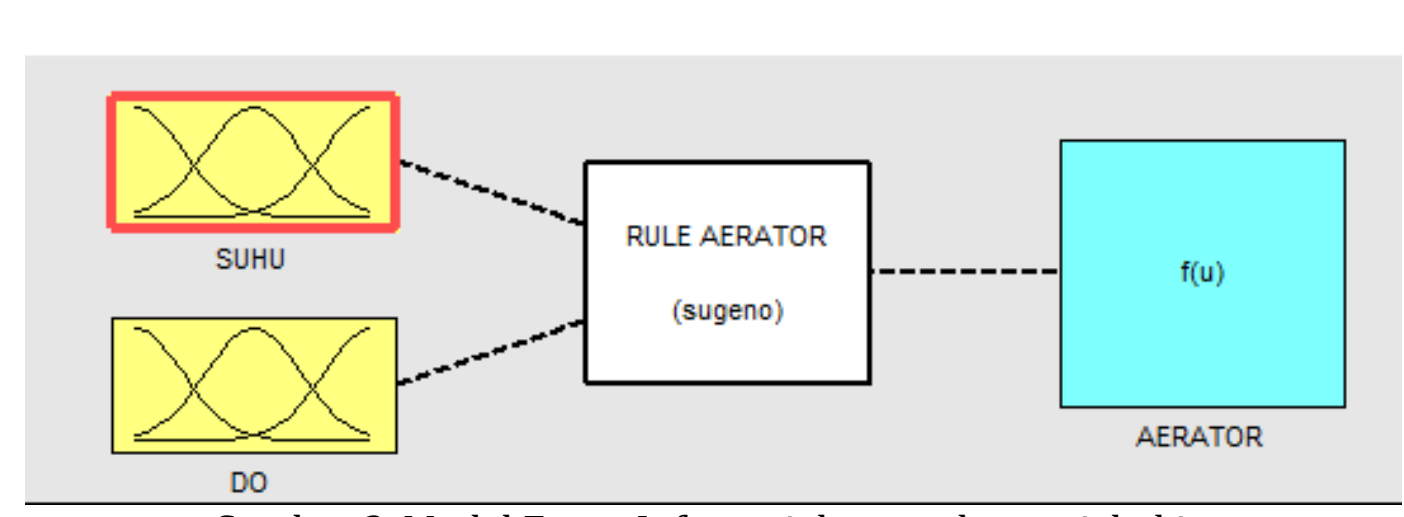

Gambar 2. Model Fuzzy Inferensi dengan dua variabel inputan

\subsection{Himpunan dan Keanggotaan Fuzzy}

Himpunan fuzzy digambarkan dalam bentuk grafik himpunan fuzzy tiap variabel dan keanggotaan fuzzy dituliskan dalam fungsi keanggotaan fuzzy $\mu(\mathrm{x})$ sebagai berikut:

\subsubsection{Himpunan keanggotaan Fuzzy DO}

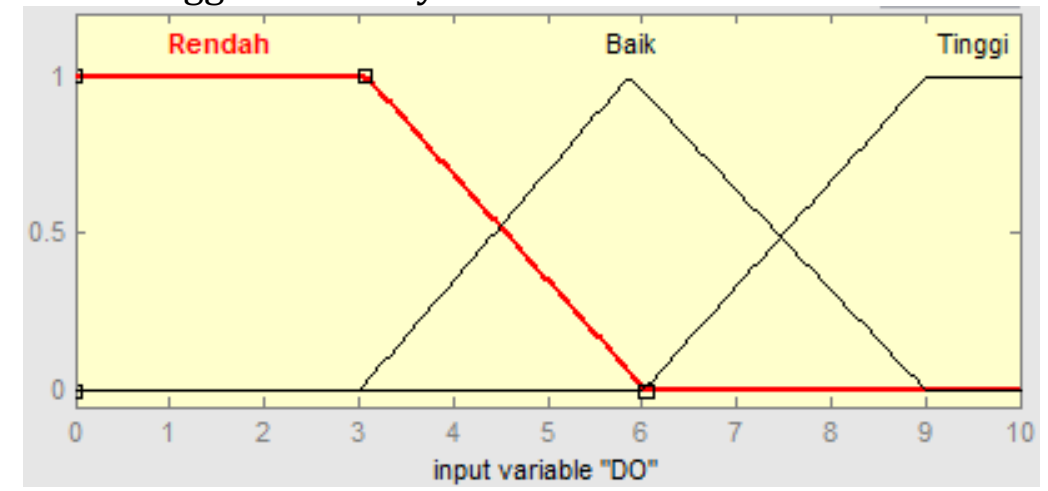

Gambar 3. Model Himpunan Fuzzy pada variabel DO

$\mu(x)$ Rendah $= \begin{cases}1 & ; x \leq 3 \\ \frac{6-x}{6-3} & ; 3<x<6 \\ 0 & ; x \geq 6\end{cases}$

$\mu(x)$ Baik $= \begin{cases}\frac{x-3}{6-3}, & 3<x \leq 6 \\ \frac{9-x}{9-6}, & 6<x<9 \\ 0, x \leq 3 & x \geq 9\end{cases}$

$\mu(x)$ Basah $=\left\{\begin{aligned} 1, & x \geq 9 \\ \frac{x-6}{9-6}, & 6<x<9 \\ 0, & x \leq 6\end{aligned}\right.$ 
3.2.1. Himpunan keanggotaan Fuzzy Suhu

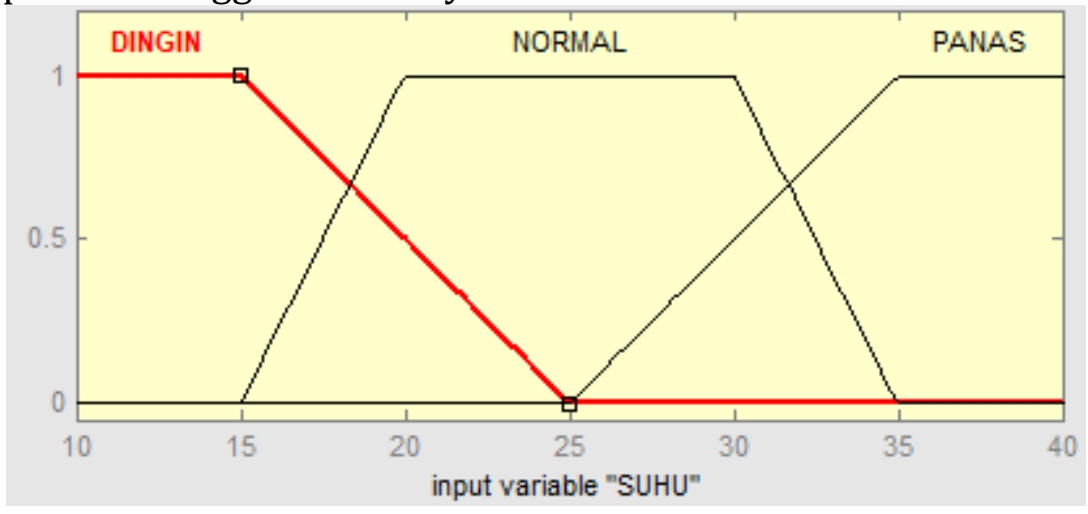

Gambar 4. Model Himpunan Fuzzy pada variabel Suhu

$\mu(x)$ Jernih $=\left\{\begin{array}{cl}1 & ; x \leq 15 \\ \frac{25-x}{25-15} & ; 15<x<25 \\ 0 & ; x \geq 25\end{array}\right.$
$\mu(x)$ Keruh $=\left\{\begin{array}{cc}\frac{1}{20-15} & ; 20 \leq x \leq 30 \\ \frac{x-15}{20-x} & ; 15<x<20 \\ \frac{35-30}{35} ; 30<x<35 \\ 0 ; x \leq 15 \text { or } x \geq 35\end{array}\right.$

$\mu(x)$ SangatKeruh $=\left\{\begin{array}{cc}1 & ; x \geq 35 \\ \frac{x-25}{35-25} & ; 25<x<35 \\ 0 & ; x \leq 25\end{array}\right.$

\subsection{Rule Base}

Terdapat 7 Rule base yang yang diperoleh dari hasil analisis, untuk himpunan variabel tingakat DO dan variabel untuk suhu air, akan menghasilkan satu output berupa seberapa lama mesin aerator berfungsi dan berapa banyak tingkat gelumbung, dan hubungan rule kedua variabel inputan tersebut dapat di lihat sebagai berikut:

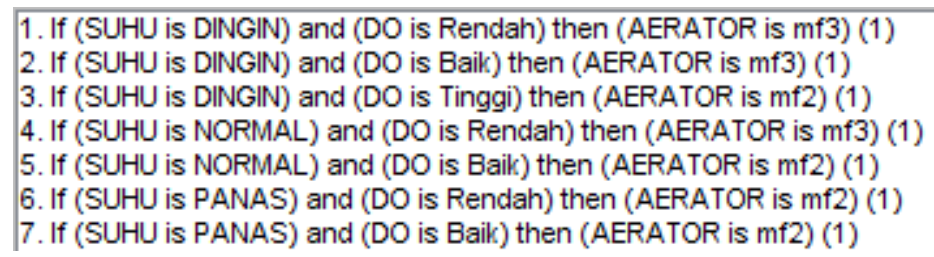

Gambar 9. Rule base hasil Analisis Fuzzy untuk Aerator 


\section{Grafik Output model}

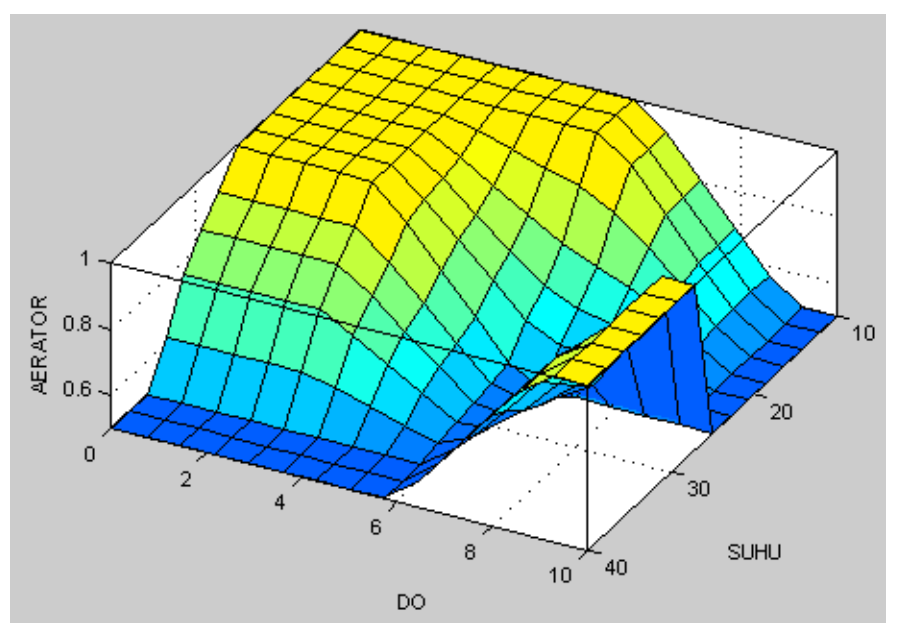

Gambar 5. Grafik Analisis hubungan antara input dan output yang dihasilkan dari Rule untuk Aerator

\subsection{Parameter luaran Keputusan}

Parameter luaran merupakan fungsi linear konstanta pada luaran fuzzy sugeno yaitu On-sebentar=0,1, On-sedang=0,5 dan On-lama=1. Yang berfungsi memberikan luaran output berupa konstanta.

\subsection{Defuzzyfication dengan metode Sugeno}

Defuzzyfikasi sugeno diselesaikan dengan menggunakan persamaan: $\mathrm{z}=\left(\mathrm{w} 1 * \mathrm{C} 3+\mathrm{w} 22^{*} \mathrm{C} 3+\mathrm{w} 33^{*} \mathrm{C} 3+\mathrm{w} 4^{*} \mathrm{C} 1+\mathrm{w} 5^{*} \mathrm{c} 2\right) /(\mathrm{w} 1+\mathrm{w} 2+\mathrm{w} 3+\mathrm{w} 4+\mathrm{w} 5)$;

\subsection{Luaran Hasil Analisis}

Tampilan luaran pada matlab

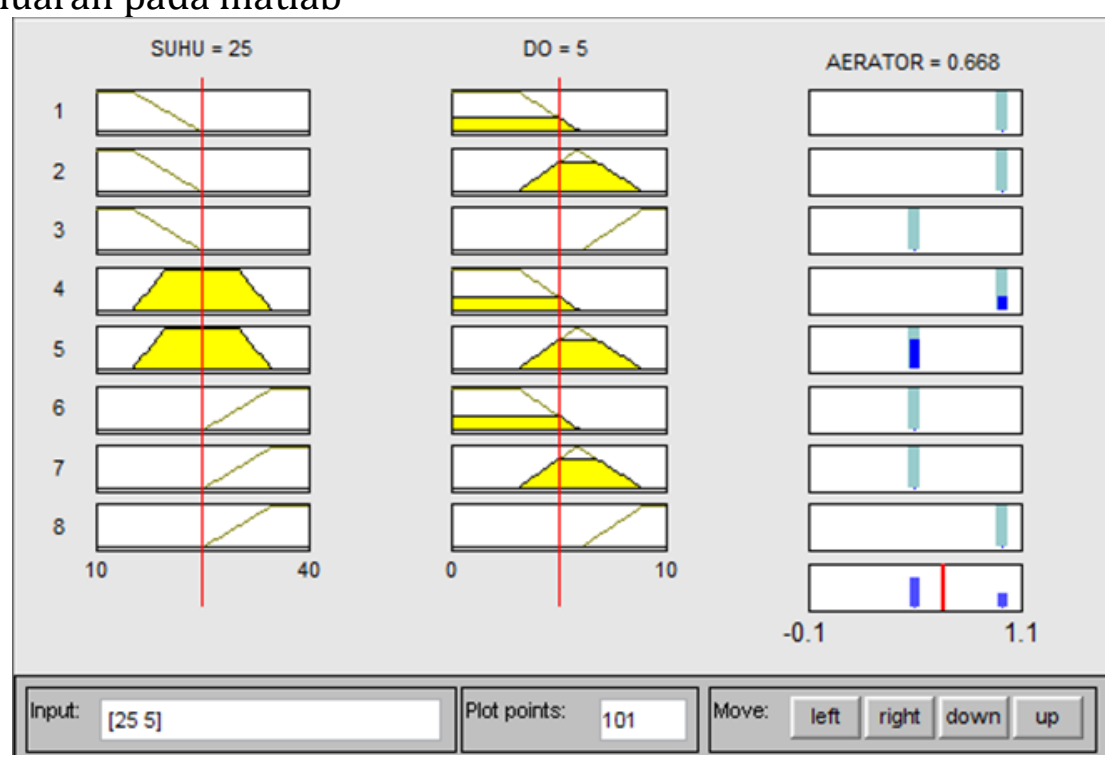




\section{Gambar 6. Hasil Luaran pada inferensi Fuzzy Sugeno}

\section{Desain Sistem}

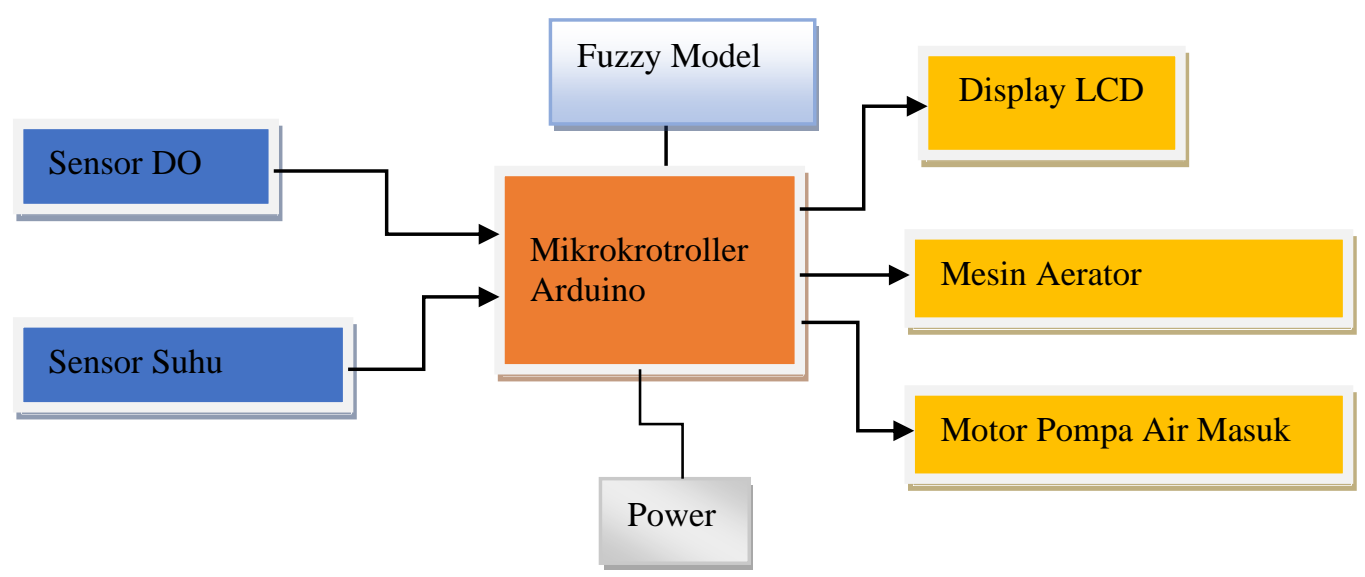

Gambar 7. Desain Model Input output

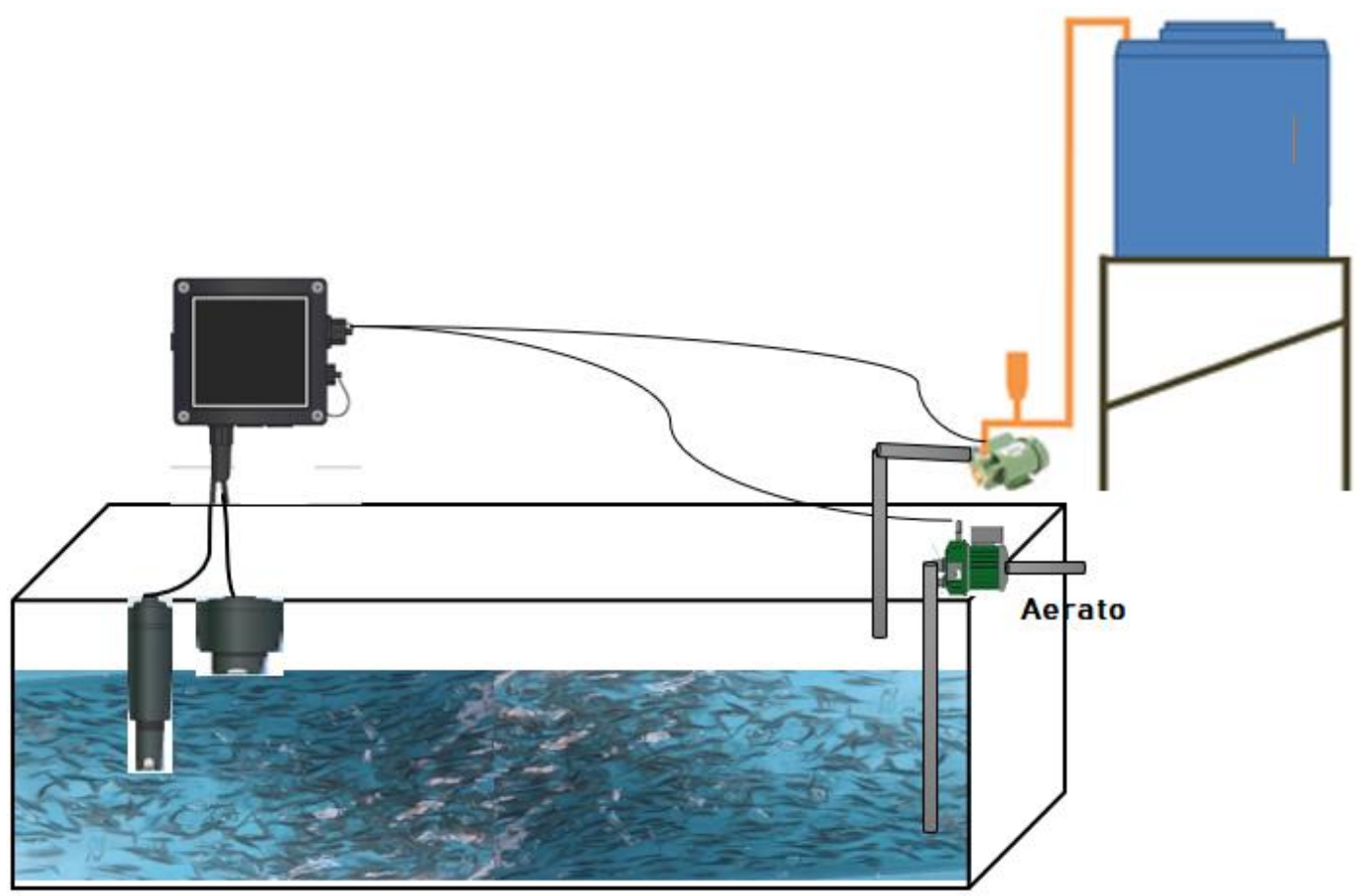

Gambar 8 Gambar Desain Sistem Manajemen Kualitas Air 


\section{SIMPULAN}

Sistem Analisis yang di buat kemudian diimplementasikan dalam desain yang dikembangkan dengan menggunakan metode fuzzy inferensi dengan defuzzyfikasi menggunakan metode Sugeno, sistem didesain mampu menyesuaikan dan memasukkan oksigen yang disemburkan menggunakan aerator, ketika keadaan kualitas air menurun dan melakukan pengecekan ulang sampai kondisi kolam pembibitan memberikan hasil dengan kualitas air yang diharapkan sesuai keadaan rule fuzzy yang telah ditetapkan.

\section{DAFTAR PUSTAKA}

[1] Durkin, J. "Expert Systems Design and Development. New Jersey", Hall International Inc.

[2] Farmadi, "Implementasi Internet of Things (IoT) pada Sistem Monitoring Rumah Kaca dengan menggunakan Mikrokontroler yang tertanam Sitem Fuzzy", Prosiding Soliter Vol 1, Oktober 2017

[3] Farmadi, Dodon. "Sistem Fuzzy Logic Tertanam pada Mikrokontroler untuk Penyiraman Tanaman pada Rumah Kaca", Jurnal Klik-Volume 04, No.02 September 2017

[4] Farmadi, Ichsan, “Implementasi Fuzzy Sugeno Untuk Menentukan Kesesuaian Tanaman Kelapa Sawit Pada Lahan Gambut", Jurnal Klik-Volume 05, No.02 September 2018

[5] Kusumadewi, Sri. Dkk. "Pengantar Kecerdasan Buatan Sistem Pakar". Graha Ilmu, Yogyakarta, 2008. 